\title{
Corrosion Resistance Test of Electroplated Metals using Fast Electrochemical Non-Destructive Analysis
}

\author{
Walter Giurlani 1,*, Patrick Marcantelli ${ }^{1}$, Francesco Benelli ${ }^{1}$, Daniele Bottacci ${ }^{2}$, \\ Filippo Gambinossi ${ }^{1}$, Maurizio Passaponti ${ }^{1}$, Emanuele Salvietti ${ }^{1}$, Antonio De Luca ${ }^{1}$ \\ and Massimo Innocenti ${ }^{1}$ \\ 1 Dipartimento di Chimica, Università degli Studi di Firenze, via della Lastruccia 3, 50019 Sesto, \\ Fiorentino, Italy; patrick.marcantelli@unifi.it (P.M.); francesco.benelli@stud.unifi.it (F.B.); \\ gambinossi@gmail.com (F.G.); maurizio.passaponti@unifi.it (M.P.); emanuele.salvietti@unifi.it (E.S.); \\ antonio.deluca@unifi.it (A.D.L.); minnocenti@unifi.it (M.I.) \\ 2 Metrohm, Ionenstrasse, Herisau, Appenzell Ausserrhoden 9100, Switzerland; daniele.bottacci@metrohm.it \\ * Correspondence: walter.giurlani@unifi.it; Tel.: +39-055-522-5250
}

Received: 15 February 2019; Accepted: 5 March 2019; Published: 13 March 2019

\begin{abstract}
Corrosion testing is a very important step in quality control for metal industrial processes. EIS is a versatile procedure for the accelerated evaluation of the anti-corrosion performance of coatings: unlike other standard procedures is generally a non-destructive method. EIS works applying an electrical sinusoidal perturbation with a fixed frequency and measuring electrical impedance $Z$ of the sample. Measuring impedance at different frequencies and analysing the data, it is possible to postulate the structure of an equivalent circuit and extract corrosion resistance data. This approach is commonly used for high-impedance coatings, in this study we explore EIS as well as the OCP measurement, the corrosion current and other techniques to find the best option for low-impedance metallic coatings analysis. The objective of this study is to develop a method to determine corrosion resistance for electroplated goods that can give results as reliable as other more diffuse and traditional destructive corrosion testing techniques (such as corrosion tests in artificial atmosphere ISO 17228, ISO 9227 and ISO 4524) with a non-destructive process and in a fair less amount of time.
\end{abstract}

Keywords: corrosion; metal coatings; impedance spectroscopy; accelerated testing; salt spray test; EIS; electroplated goods

\section{Introduction}

The metals are normally exposed to corrosion in atmospheric and aqueous environments; in many industrial sectors metallic corrosion is a well-known of the problems, for this reason often protective coating are applied to the bare metal. There are many typology of coatings: insulating like plastics, paints and passivation or conductive like galvanic protection or noble element deposition. The uses of these technique ranges from fashion accessories, used in jewellery, bags, belts, etcetera to the automotive sector and in the construction sector where an example can be the bars of the concrete [1-3]. So the development of new alloys or coatings takes on a fundamental aspect for the prevention of corrosion, because all this has negative implications both from an aesthetic point of view and from a point of view of environmental safeguarding, like in the collapse of structures. In order to avoid these problems, it is important to check the corrosion status of the materials.

Nowadays, while for the insulating coating exist electrochemical studies and regulations, for the assessment of corrosion on metal films is carried out through long and destructive tests such as: the $24 \mathrm{~h}$ synthetic sweat test [4], the corrosion test with thioacetamide [5] with a duration of $48 \mathrm{~h}$, the 
$24 \mathrm{~h}$ sulphur dioxide test [6], the $24 \mathrm{~h}$ damp heat test [7] and the $48 \mathrm{~h}$ salt spray test [8]. After performing the tests, the corrosion assessment of the metallic coatings is carried out by a visual comparison. It seems clear that until today, in literature there is no tool that expresses a certain numerical value to identify if a metallic coating has undergone to corrosion.

In facts visual comparison lead only to a quantitative estimation but not a qualitative one. The aim of this work was to test electrochemical methods for the evaluation of corrosion in metal coatings using cumulative charge, Open Circuit Potential (OCP) and Electrochemical Impedance Spectroscopy (EIS) measurements, combined to the application of a stress potential, there may be applications both in industry and in scientific research in the case of conductive film studies [9-16]. Although this technique is already used for the study of materials coated with paints and organic materials [17-19], no study has been carried out on metallic coatings. For this reason, we use methodology that combined the studies on insulating coatings and uncoated metals [20-26], to obtain a faster, alternative, non-visually destructive, quantitative and modulable method for the evaluation of corrosion of metallic coatings, compared to the current methods used in the galvanicindustries.

\section{Materials and Methods}

The samples were prepared on a metal substrate of $3.75 \mathrm{~mm} \times 5 \mathrm{~mm}$ brass (copper-zinc 67:33 alloy) plates, $0.25 \mathrm{~mm}$ thick. We used commercial electrodeposition solution of copper, white brass, palladium and gold. The sequence of the layers and their thickness is shown in Table 1. We used typical galvanic bath used in jewellery industry with the same ranges of thicjknesses and layer sequences [1]. To have a simple system we used only a single non-precious metal layer and one precious layer, since gold is not stable if electroplated directly on copper, due to the solubility of the two metal one in the other and the consequent diffusion over time, gold was electroplated on bronze and palladium on copper. The characteristics of the single layers are the following: copper tends to suffer corrosion, bronze tends to passivation as well as palladium (even if palladium is nobler), and finally gold should be not attacked by corrosion.

Table 1. Composition and thicknesses of the samples.

\begin{tabular}{cccccc}
\hline Sample & Base Metal & $\mathbf{C u}(\mu \mathrm{m})$ & Bronze $(\mu \mathrm{m})$ & Pd $(\mu \mathrm{m})$ & $\mathbf{A u}(\mu \mathrm{m})$ \\
\hline Au0.3 & Brass & $>5$ & $4.46 \pm 0.62$ & - & $0.36 \pm 0.02$ \\
Au0.6 & Brass & $>5$ & $4.46 \pm 0.62$ & - & $0.74 \pm 0.09$ \\
Au1.0 & Brass & $>5$ & $4.46 \pm 0.62$ & - & $1.04 \pm 0.07$ \\
Pd0.3 & Brass & $>5$ & - & $0.36 \pm 0.07$ & - \\
Pd0.6 & Brass & $>5$ & - & $0.67 \pm 0.03$ & - \\
Pd1.0 & Brass & $>5$ & - & $1.11 \pm 0.06$ & - \\
\hline
\end{tabular}

Atomic force microscopy (AFM) (PicoSPM, Molecular Imaging, Tempe, AZ, USA) was used evaluate the roughness of the samples. The measurements were performed in contact mode with a non-conductive $\mathrm{Si}_{3} \mathrm{~N}_{4}$ triangular cantilever (NP-S10, Veeco, Plainview, NY, USA), the cantilever depth was in the $0.4-0.7 \mu \mathrm{m}$ range and with a force consent of $0.12 \mathrm{~N} / \mathrm{m}, 0.5 \mathrm{~V}$ force set point and a speed of $1.21 / \mathrm{s}$.

XRF measurements were performed with a Bowman B Series XRF spectrometer (Schaumburg, IL, USA) using an acquisition time of $60 \mathrm{~s}, 50 \mathrm{kV}$ tube voltage, $0.8 \mathrm{~mA}$ tube current, ad a focal distance of $12 \mathrm{~mm}$ and with a collimator of $0.305 \mathrm{~mm}$ in diameter.

The electrochemical measurements were performed with a Metrohm Autolab (Utrecht, The Netherlands) PGSTAT204 potentiostat controlled by the NOVA 2.1.3 software. The electrochemical cell consists in a polymethylmethacrylate cylinder, $5 \mathrm{~cm}$ in diameter and $1 \mathrm{~cm}$ long, with a hole of $11.3 \mathrm{~mm}$ in diameter along its axis to contain $1 \mathrm{~mL}$ of solution. Measurement was performed with the three electrode setup. The working electrode (our samples) and the counter electrode (Pt foil) were disposed on the two sides of the cylinder and screw sealed with PMMA plug. Through a small lateral hole, the $\mathrm{Ag} / \mathrm{AgCl} / \mathrm{sat}$. $\mathrm{KCl}$ reference electrode is immersed in the solution. The solution contains $3.5 \mathrm{wt} \% \mathrm{NaCl}$ (Sigma Aldrich, Saint Louis, MO, USA; $\geq 99 \%$ ) ant 
is buffered at $\mathrm{pH} 7$ with $0.1 \mathrm{M} \mathrm{NaH}_{2} \mathrm{PO}_{4} / \mathrm{Na}_{2} \mathrm{HPO}_{4}$.

The classical corrosion tests performed was $24 \mathrm{~h}$ damp heat ISO 17228:2015 [7], $48 \mathrm{~h}$ salt spray

ISO 9227:2017 [8] and $24 \mathrm{~h}$ sulphur dioxide ISO 4524:2000 [6].

\section{Results}

The thickness of the coatings was measured using the XRF, the results are shown in Table 1. The samples are named with the primary element in the composition of the final coating, followed by the nominal thickness. The real thickness could be slightly different from the nominal one but the distribution was calculated, in fact six sample of each type was prepared to perform all the planned experiments.

In addition to all the other samples two more were prepared to study the roughness of the substrate. The top layer of the first one was bronze, the substrate of the gold samples, while the other was copper, used as substrate for the palladium samples. We performed the AFM analysis of the substrates (Figure 1) to calculate the RMS of the heights. The founded roughness, $10.0 \mathrm{~nm}$ for $\mathrm{Cu}$ and $10.3 \mathrm{~nm}$ for bronze, was much lower than the lowest deposit in the gold and the palladium samples, confirming that we can consider the deposit as homogeneous.

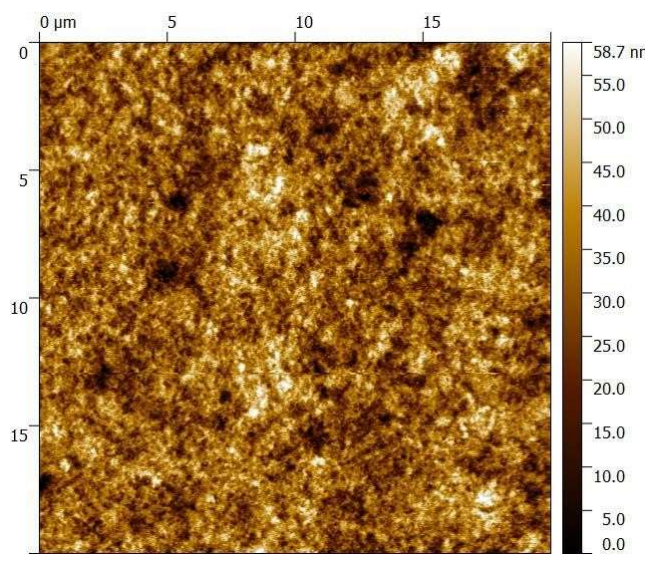

(a)

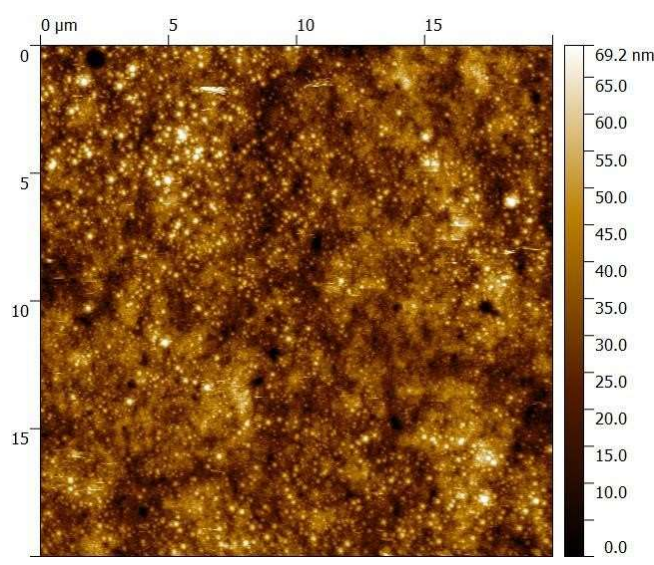

(b)

Figure 1. AFM images of the electroplated substrates: (a) bronze; (b) copper.

\subsection{Polarization Plots}

The first electrochemical characterization of the samples was made performing a long time OCP measurement and a subsequent polarization curve. The OCP was recorded for $16 \mathrm{~h}$ on the two substrate (copper and brass) and on the Au1.0 and Pd1.0 samples, to observe the time needed to obtain a stable reading of the corrosion potential $E_{\text {corr }}$ and also to observe if there was any drifting. The samples with the higher thickness was chosen for this measurement since we want to isolate the contribution of the top layer alone. The results show (Figure 2) little fluctuations only in the early stages of the measurement and a very light drift for almost alt the samples except for the Bronze which keeps increasing its OCP value even after $16 \mathrm{~h}$, in fact bronze start at $-0.35 \mathrm{~V}$ and stops over $-0.10 \mathrm{~V}$, crossing the $\mathrm{Cu}$ value at $-0.2 \mathrm{~V}$ after 2 hours and a half. This is due to the formation of an oxide layer on the surface of the bronze. There is also a cross between Au1.0 and Pd1.0 samples due to the rising of Au1.0, but the variation over the total time is almost negligible. 


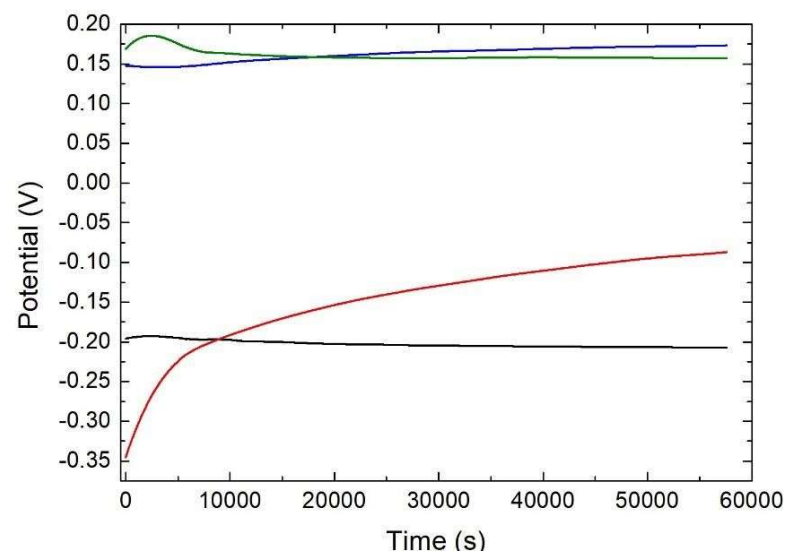

Figure 2. OCP measutement over $16 \mathrm{~h}$ of copper (black), bronze (red), palladium (blue) and gold (green).

The polarization curve was performed from -0.25 to $+1.3 \mathrm{~V}$ respect to the OCP value (the average on the last 50 points was considered) with a scan speed of $0.4 \mathrm{mV} / \mathrm{s}$. The results are showed in Figure 3 , copper reach a high current passive-like zone after the corrosion peak above $0.25 \mathrm{~V}$; Also bronze own a passive zone after the same potential but with much lower currents; Palladium has a corrosion peak at 0.6 and over $1 \mathrm{~V}$ the current rises probably due to the oxidation of water; gold has a small corrosion peak near the $E_{\text {corr }}$ and another one muck more intense at $0.9 \mathrm{~V}$, then the water oxidation takes place. Since the bronze suffer a drifting during the OCP measurement, for comparison it was measured another polarization curve of it after an OCP of $1 \mathrm{~h}$. In this case the Ecorr occurs at much more negative potentials, as expected, but there is also a corrosion peak, at $0.0 \mathrm{~V}$ that was not present the previous measurement.

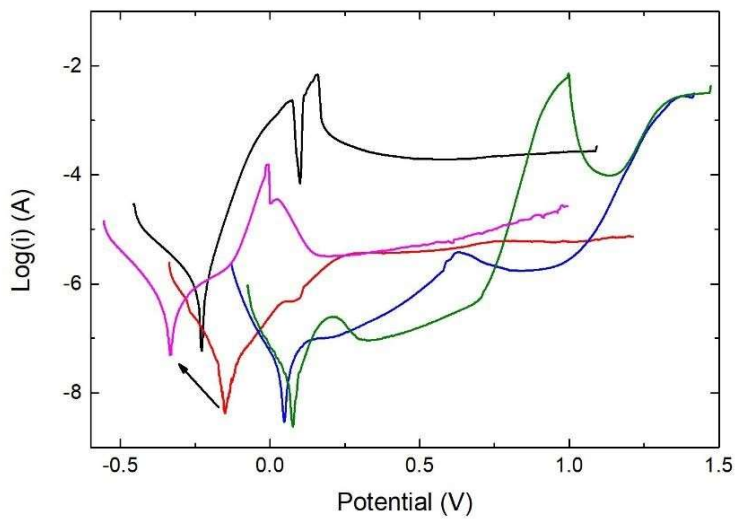

Figure 3. Polarization curvesrecorded between -0.25 and $+1.3 \mathrm{~V}$ respect to the OCP after 16 hours copper (black), bronze (red), palladium (blue) and gold (green). The measurement was performed also after the measurement of the OCP for 1 hour in the case of bronze(pink).

\subsection{Classical Corrosion Tests}

All the samples were subjected to three commonly used accelerating corrosion test: damp heat, salt spray and sulphur dioxide (Figure 4). The coatings were smooth and without imperfection that the damp test and sulphur dioxide were not able to attack even the lower thickness. Only the salt spray exhibited some variation before and after the test: gold samples with lower thickness appears more reddish and all the sample present a white line, due to the inclusion of the salt, along the diagonal because of their position in the test chamber, little amount of greenish salt was spotted near the holes (weak points) used to hang up the plates during the sample preparation. 


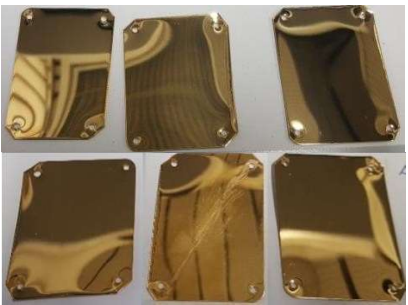

$\mathrm{Au} 0.3$

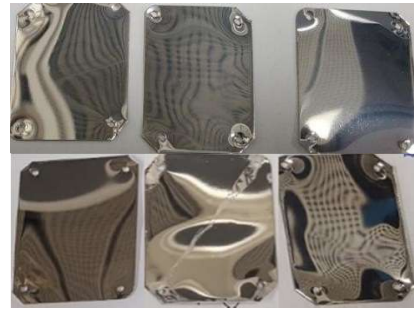

$\operatorname{Pd} 0.3$

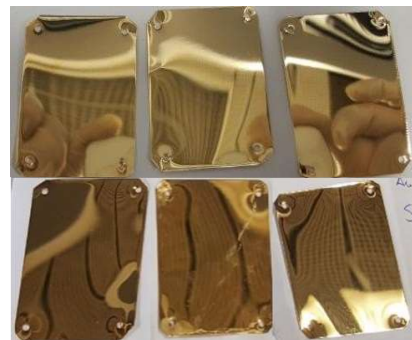

Au0.6

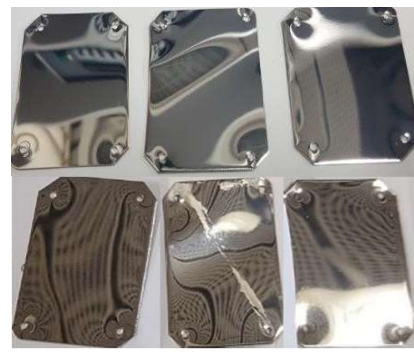

Pd0.6

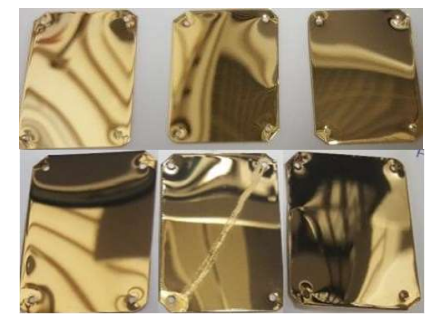

Au1.0

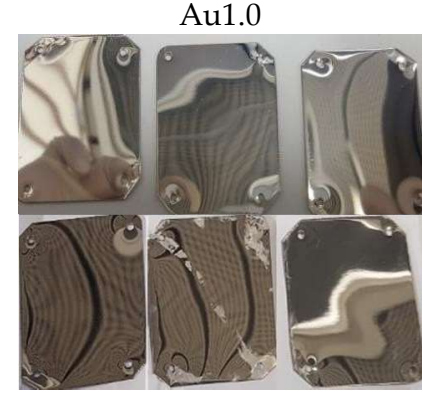

Pd1.0

Figure 4. Pictures off all the samples taken before and after the chemical corrosion tests. The three top images in each cell corresponds to the before, while the after is on the bottom, the performed test from left to right are: dump heat, salt spray and sulphur dioxide.

\subsection{Elecrochemical Tests}

The electrochemical test was performed as follow: (1) 5 min OCP measurement; (2) initial EIS measurement from $100 \mathrm{kHz}$ to $10 \mathrm{~Hz}$ with 10 samplings perdecades; (3) repeated 12 times: application of a stress potential for $30 \mathrm{~min}$ and charge sampling; 5 min relaxation and OCP measurement; (4) final EIS measurement from $100 \mathrm{kHz}$ to $10 \mathrm{~Hz}$ with 10 samplings per decades

We chose to limit the OCP measurement to 5 minutes to shorten the time needed for the complete test, also considering that the precious top coating reaches a stable goal quickly as seen in Figure 2. We chose two different stress potential: $+20 \mathrm{mV}$ and $+100 \mathrm{mV}$ respect to the last measured OCP. For all samples after the stresses no visual modification was observed even if their electrochemical behaviour changed. The corrosion was evaluated recording three signals: cumulative charge during the stresses (Figure 5), OCP before and after every stress (Figure 5) and EIS before and after the stresses (Figure 6). For comparison the OCP and the EIS measurement was performed also on the samples subjected to the salt spray, before and after the test. The EIS measurement was reported with the Nyquist plots. The charge gives a qualitative information of the corrosion resistance, in fact high amount of charge may be due to the oxidation of coating and low quantity to resistance but also passivation will lead to make pass only little currents. The amount of charge that pass in the gold samples in higher than for palladium, while the OCP is lower; except for Au1.0, in all the samples the charge is higher for the treatments at $+100 \mathrm{mV}$ respect to $+20 \mathrm{mV}$, as expected.

During the test at $+20 \mathrm{mV}$ for the Au0.3 the charge tends to increase of one order of magnitude suggesting that modifications are taking place in on the surface, while the other two gold samples exhibit a stable trend. The OCP in these samples remains quite constant during the cycles. Also in the Nyquist plot there is no big changes in the impedance values (Figure 6a), this was ascribed to the resistance of the coating to the corrosion. In all the gold samples, during the $+100 \mathrm{mV}$ stress, it was recorded a high amount of charge in the first two cycles, then the current drops, this behaviour was more evident for Au1.0 than the other samples. In this case the OCP goes up in the first two cycles and then falls back in the following ones, meaning that modification takes place on the surface. Also the Nyquist plot shows big changes (Figure 6b) and it is interesting to notice that after the faradic treatment the slope of the curve differs less increasing the thickness. The EIS measurement performed before and after the salt spray test (Figure 6c) are quite similar to those obtained with the $+20 \mathrm{mV}$ stress. The palladium samples exhibit a similar trend during both the two stresses and for all the thicknesses: the amount of charge decrease of ten times and the OCP increase during the cycles, this 
behaviour was ascribed to the passivation of the metal. This trend is more evident for the thinner samples. The Nyquist plot does not change a lot after the $+20 \mathrm{mV}$ treatment on the palladium samples (Figure 6d), while it is evident the effects after the $+100 \mathrm{mV}$ ones (Figure 6e): in fact, also in this case the slope of the curve differs less increasing the thickness, in addition to that the final slope of Pd0.3 and Pd0.6 is lower than the initial, indicating corrosion, while in the case of Pd1.0 it is higher, indicating passivation. Similar behaviour emerged in the measurement performed on the samples subjected to the salt spray test (Figure 6f).

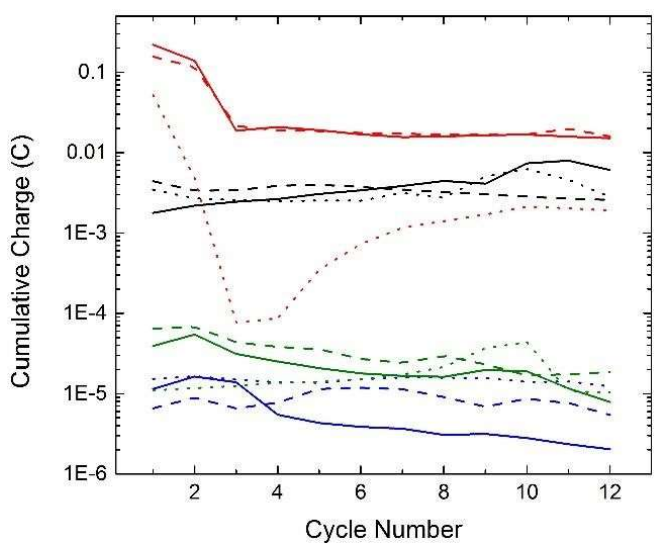

(a)

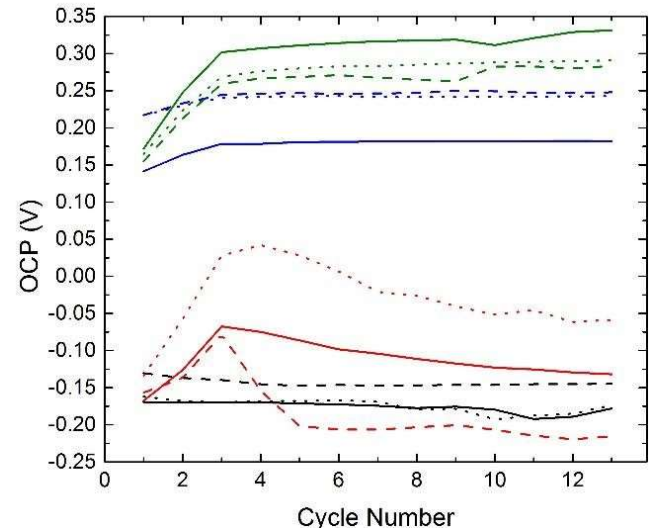

(b)

Figure 5. Cumulative charge plot (a) and OCP variation (b) during the electrochemical stress. Au +20 mV (black), Au +100 mV (red), Pd +20 mV (blue), Pd +100 mV (green); 0.3 samples (solid line), 0.6 samples (dash line), 1.0 samples (dot line).

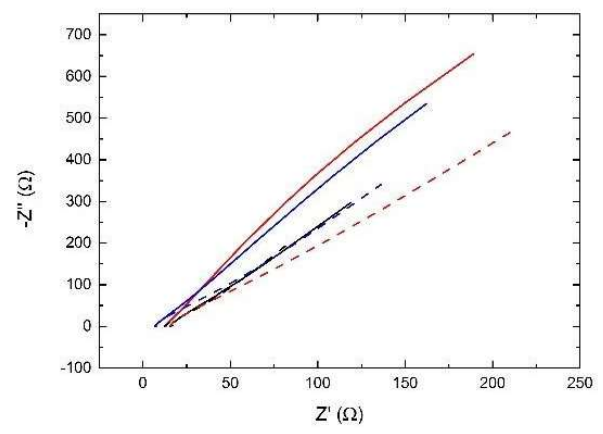

(a)

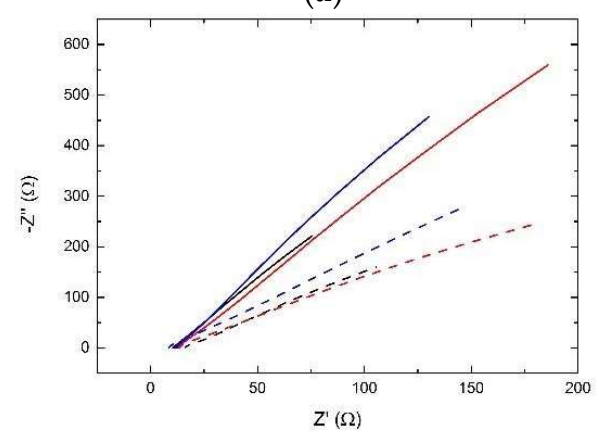

(c)

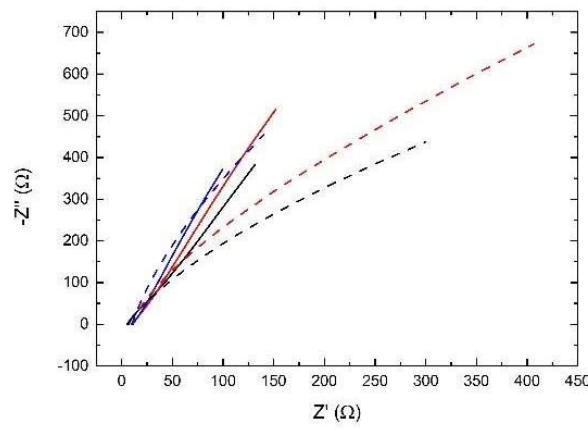

(b)

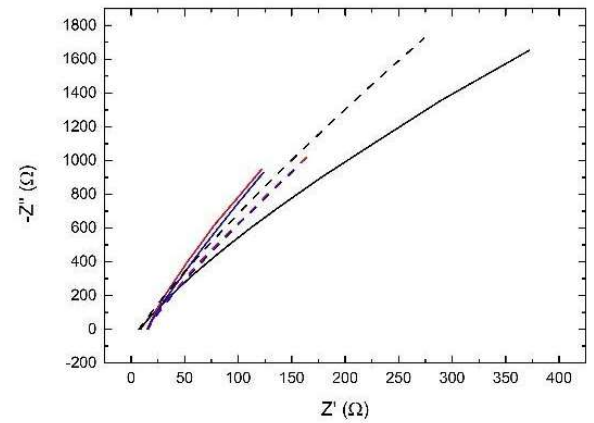

(d)

Figure 6. Cont. 


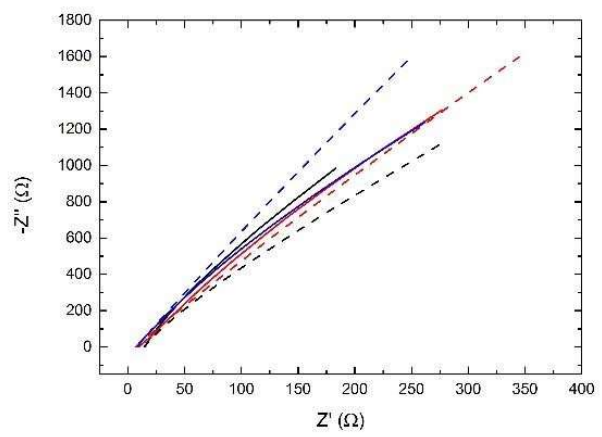

(e)

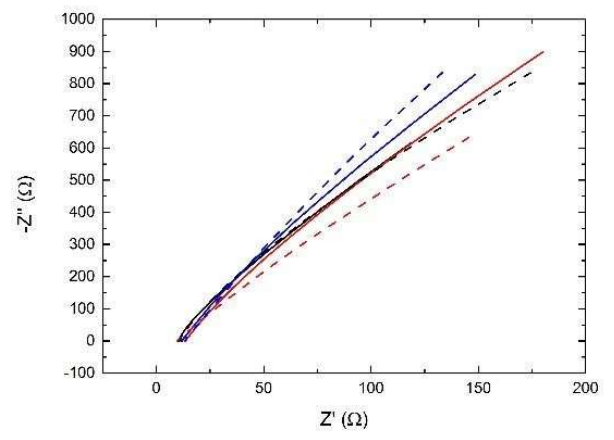

(f)

Figure 6. Nyquist plot before (solid line) and after (dash line) of the gold samples with $+20 \mathrm{mV}$ stress (a), $+100 \mathrm{mV}$ stress (b) and salt spray test (c) and the palladium samples with $+20 \mathrm{mV}$ stress (d), +100 $\mathrm{mV}$ stress (e) and salt spray test (f); 0.3 samples (black), 0.6 samples (red), 1.0 samples (blue).

Another formalism to report impedance variation in corrosion is $\Delta Z \%$. The data were treated considering the relative variation of the logarithmic value of the impedance module (bode plot) at the lowest frequency $(10 \mathrm{~Hz})$, named $\Delta Z \%$, as shown by Equation (1):

$$
\Delta Z \%=\frac{\log \left(\left|Z_{f}\right|\right)-\log \left(\left|Z_{i}\right|\right)}{\log \left(\left|Z_{i}\right|\right)}
$$

Figure 7a,b showed the results of the gold and palladium samples. It is possible to notice that the electrochemical tests are more consistent than the results obtained with the saltspray test, which appear more scattered. The results also confirm the previous deductions: the treatment at +20 does not attack significantly neither of the two metals, in fact $\Delta Z \%$ is close to 0 or even negative. Instead, after the application of $+100 \mathrm{mV}$, all the sample owns an increment in $\Delta Z \%$. However, there are not significant differences for different thicknesses of the same metal, this could be due to the fact that using $\Delta Z \%$ the information about the real (resistance) and the imaginary (reactance) parts of the impedance are lost so cannot be distinguished between corrosion and passivation.

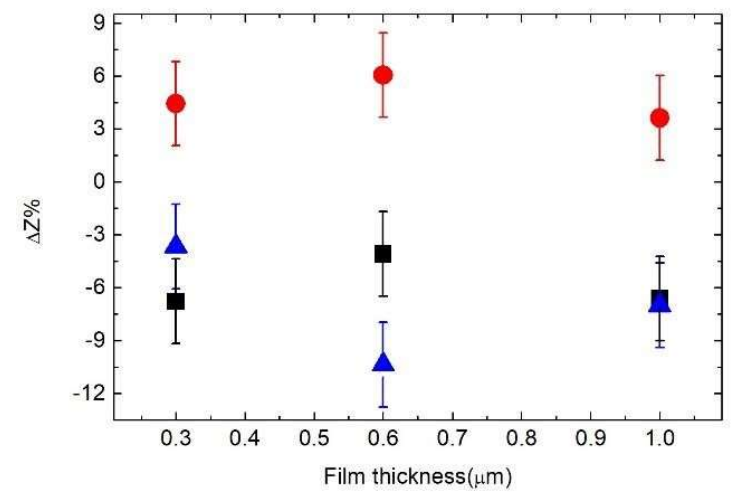

(a)

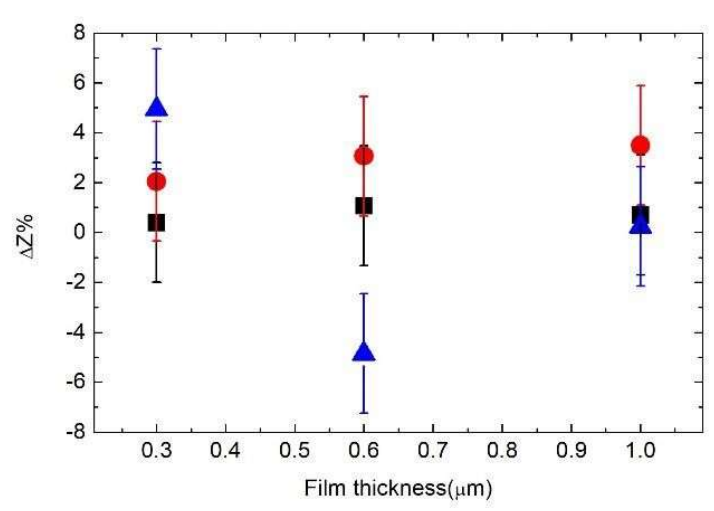

(b)

Figure 7. Comparison after the $+20 \mathrm{mV}$ stress (black), $+100 \mathrm{mV}$ stress (red) and salt spray test (blue) of the calculated $\Delta Z \%$ value for the gold (a) and the palladium (b) samples.

\section{Conclusions}

In this paper we evaluate the corrosion of metal coatings using electrochemical methods. EIS is a common technique used to test insulating coatings and paints but not many studies are present to test the resistance of metal films. Nowadays this kind of samples are tested with long and destructive methodology. In this study we experiment three different thicknesses of commonly electroplated alloys in precious galvanic industry: gold films on bronze and three of palladium on copper, namely a noble metal deposited on a not precious one. The results were also compared with more classical 
tests. The proposed method is not visually destructive, lead to numerical results (instead of visual comparison), the stress could be easily modulated and needs about $8 \mathrm{~h}$ (compared to the 24 or $48 \mathrm{~h}$ of chemical tests) but could be even faster if the number of cycles is reduced or the potential stress increased. On the other hand, the interpretation of the results is not immediate, we evaluate the cumulative charge and OCP trends, Nyquist plot variation and $\Delta Z \%$. For this reason, even if this technique shows high potentials, more study must be done on samples with different thickness and composition to find which parameter, or parameters, are more significant for a simple interpretation of metal film corrosion.

Author Contributions: Conceptualization, W.G.; Methodology, W.G.; Investigation, F.B.; Data Curation, W.G. and F.B.; Writing-Original Draft Preparation, W.G. and F.B.; Writing-Review \& Editing, P.M., F.G., M.P., E.S. and A.D.L.; Supervision, W.G. and D.B.; Project Administration, M.I.; Funding Acquisition, M.I.

Funding: This research was funded by Regione Toscana POR CreO FESR 2014-2020-azione 1.1.5 sub-azione a1 Bando 2 "Progetti di ricerca e sviluppo delle MPMI" which made possible the project "Gioielli in Argento Da Galvanica Ecologica e Tecnologica" (GADGET) and "Tecnologia al plasma per l'industria del lusso: una manifattura innovativa nel comparto accessori in ottica 4.0" (THINFASHION).

Acknowledgments: The authors acknowledge Metrohm s.r.l. for the technical support and the devices made available.

Conflicts of Interest: The authors declare no conflict of interest.

\section{References}

1. Giurlani, W.; Zangari, G.; Gambinossi, F.; Passaponti, M.; Salvietti, E.; Di Benedetto, F.; Caporali, S.; Innocenti, M. Electroplating for decorative applications: Recent trends in research and development. Coatings 2018, 8, 260.

2. Femenias, Y. S.; Angst, U.; Moro, F.; Elsener, B. Development of a novel methodology to assess the corrosion threshold in concrete based on simultaneous monitoring of $\mathrm{pH}$ and free chloride concentration. Sensors 2018, 18, 3101.

3. Elsener, B.; Andrade, C.; Gulikers, J.; Polder, R.; Raupach, M. Half-cell potential measurements - Potential mapping on reinforced concrete structures. Mater. Struct. Constr. 2003, 36, 461-471.

4. ISO 3160-2:2015 Watch-Cases and Accessories-Gold Alloy Coverings-Part 2: Determination of Fineness, Thickness, Corrosion Resistance and Adhesion; International Organization for Standardization: Geneva, Switzerland, 2015.

5. ISO 4538:1978 Metallic Coatings-Thioacetamide Corrosion Test (TAA Test); International Organization for Standardization: Geneva, Switzerland, 1978.

6. ISO 4524-2:2000 Metallic coatings-Test Methods for Electrodeposited Gold and Gold Alloy Coatings-Part 2: Mixed Flowing Gas (MFG) Environmental Tests; International Organization for Standardization: Geneva, Switzerland, 2000.

7. ISO 17228:2015 (IULTCS/IUF 412) Leather-Tests for Colour Fastness-Change in Colour with Accelerated Ageing; International Organization for Standardization: Geneva, Switzerland, 2015.

8. ISO 9227:2017 Corrosion Tests in Artificial Atmospheres-Salt Spray Tests; International Organization for Standardization: Geneva, Switzerland, 2017.

9. Loglio, F.; Innocenti, M.; D’Acapito, F.; Felici, R.; Pezzatini, G.; Salvietti, E.; Foresti, M.L. Cadmium selenide electrodeposited by ECALE: Electrochemical characterization and preliminary results by EXAFS. J. Electroanal. Chem. 2005, 575, 161-167.

10. Guidelli, R.; Foresti, M.L.; Innocenti, M. Two-dimensional phase transitions of chemisorbed uracil on Ag(111): Modeling of short- and long-time behavior. J. Phys. Chem. 1996, 3654, 18491-18501.

11. Pezzatini, G.; Moncelli, M. R.; Innocenti, M.; Guidelli, R. Comparative adsorption study of 1-butanol and 1-pentanol on mercury and gallium from aqueous $0.5 \mathrm{M} \mathrm{Na}_{2} \mathrm{SO}_{4}$ at $32^{\circ} \mathrm{C}$. J. Electroanal. Chem. 1990, 295, 275290.

12. Becucci, L.; Innocenti, M.; Salvietti, E.; Rindi, A.; Pasquini, I.; Vassalli, M.; Foresti, M. L.; Guidelli, R. Potassium ion transport by gramicidin and valinomycin across a $\mathrm{Ag}(111)$-supported tethered bilayer lipid membrane. Electrochim. Acta 2008, 53, 6372-6379. 
13. Failli, P.; Bani, D.; Bencini, A.; Cantore, M.; Mannelli, L.D.C.; Ghelardini, C.; Giorgi, C.; Innocenti, M.; Rugi, F.; Spepi, A.; et al. A novel manganese complex effective as superoxide anion scavenger and therapeutic agent against cell and tissue oxidative injury. J. Med. Chem. 2009, 52, 7273-7283.

14. Innocenti, M.; Loglio, F.; Pigani, L.; Seeber, R.; Terzi, F.; Udisti, R. In situ atomic force microscopy in the study of electrogeneration of polybithiophene on Pt electrode. Electrochim. Acta 2005, 50, 1497-1503.

15. Cecconi, T.; Atrei, A.; Bardi, U.; Forni, F.; Innocenti, M.; Loglio, F.; Foresti, M. L.; Rovida, G. X-ray photoelectron diffraction (XPD) study of the atomic structure of the ultrathin CdS phase deposited on $\mathrm{Ag}(111)$ by electrochemical atomic layer epitaxy (ECALE). J. Electron Spectros. Relat. Phenom. 2001, 114-116, 563-568.

16. Wang, L.; Lavacchi, A.; Bevilacqua, M.; Bellini, M.; Fornasiero, P.; Filippi, J.; Innocenti, M.; Marchionni, A.; Miller, H.A.; Vizza, F. Energy efficiency of alkaline direct ethanol fuel cells employing nanostructured palladium electrocatalysts. Chem CatChem 2015, 7, 2214-2221.

17. ISO 16773:2016 Electrochemical Impedance Spectroscopy (EIS) on Coated and Uncoated Metallic Specimens; International Organization for Standardization: Geneva, Switzerland, 2016;

18. ISO/TR 16208:2014 Corrosion of Metals and Alloys-Test Method for Corrosion of Materials by Electrochemical Impedance Measurements; International Organization for Standardization: Geneva, Switzerland, 2014.

19. ISO 17463:2014 Paints and Varnishes-Guidelines for the Determination of Anticorrosive Properties of Organic Coatings by Accelerated Cyclic Electrochemical Technique; International Organization for Standardization: Geneva, Switzerland, 2014.

20. Autolab Application Note COR09. Electrochemical impedance spectroscopy of three coated aluminum samples. Available online: https://www.ecochemie.nl/download/Applicationnotes/Autolab_Application _Note_COR09.pdf (accessed on 15 February 2019)

21. Afshar, F.N.; Tichelaar, F.D.; Glenn, A.M.; Taheri, P.; Sababi, M.; Terryn, H.; Mol, J.M.C. Improved corrosion resistance of aluminum brazing sheet by a post-brazing heat treatment. Corrosion 2016, 73, 379393.

22. Díaz, B.; Freire, L.; Nóvoa, X.R.; Pérez, M.C. Electrochemical behaviour of high strength steel wires in the presence of chlorides. Electrochim. Acta 2009, 54, 5190-5198.

23. Gabrielli, C.; Keddam, M. Review of applications of impedance and noise analysis to uniform and localized corrosion. Corrosion 1992, 48, 794-811.

24. Gabrielli, C.; Maurin, G.; Mirkova, L.; Perrot, H.; Tribollet, B. Transfer function analysis of hydrogen permeation through a metallic membrane in a Devanathan cell. I. Theory. J. Electroanal. Chem. 2006, 590, 114.

25. Huang, H. H. Electrochemical impedance spectroscopy study of strained titanium in fluoride media. Electrochim. Acta 2002, 47, 2311-2318.

(C) 2019 by the authors. Licensee MDPI, Basel, Switzerland. This article is an open access article distributed under the terms and conditions of the Creative Commons Attribution (CC BY) license (http://creativecommons.org/licenses/by/4.0/). 